\title{
Coesão e Disciplina Partidária no Senado Federal $^{*}$
}

\section{Pedro Robson Pereira Neiva}

Doutor em Ciência Política pelo Instituto Universitário de Pesquisas do Rio de Janeiro (Iuperj). Pós-doutorando no Centro Brasileiro de Análise e Planejamento (Cebrap), 2010. Legislativo, metodologia quantitativa, elites, relações internacionais, são suas áreas de interesse (e-mail: prneiva@gmail.com)

Ali eles vão resolver como já resolveram tantas outras coisas que aconteceram. E queria te dizer o seguinte: é que você não conhece a força de um senador. Coitado do presidente da República, para dar conselho para um senador, ou seja, é quase humanamente impossível. A bancada do PT vai agir da melhor forma possível (resposta do presidente Lula a um jornalista, a respeito da suposta orientação que teria dado à bancada do PT no Senado, na crise que envolvia o ex-presidente Sarney).

É muito difícil julgar um colega. A gente convive muito tempo junto e acaba se vendo impedido quando tem uma relação de afinidade (senador Aloizio Mercadante (PT-SP)

em entrevista ao jornalista João Dória Júnior, quando falava sobre a crise que assola o Senado, em 8/8/2009).

\footnotetext{
* Agradeço a Fernando Limongi e a Argelina Figueiredo a oportunidade de realizar essa pesquisa no âmbito do Centro Brasileiro de Análise e Planejamento (Cebrap), para a qual contei com bolsa de pós-doutorado da Fundação de Amparo à Pesquisa do Estado de São Paulo (FAPESP) no 663-9/2007. Agradeço também a ajuda de Andréa Freitas, Júlio Costa e Maurício Izumi na montagem do banco de dados sobre o Senado, a Scott Desposato pelas dicas a respeito do fator de correção de disciplina partidária e aos pareceristas de DADOS pelos excelentes comentários. Os dados referentes a essa pesquisa podem ser disponibilizados pelo autor a partir de solicitação no e-mail prneiva@gmail.com.
}

DADOS - Revista de Ciências Sociais, Rio de Janeiro, vol. 54, n-2, 2011, pp. 289 a 318. 


\section{INTRODUÇÃO}

$\mathrm{E}$ sse artigo procura analisar o comportamento dos partidos no Senado brasileiro entre 1989 a 2009, por meio da avaliação do seu grau de disciplina/coesão interna nas votações nominais que foram realizadas na Casa. A preocupação principal é verificar se a previsão de parte da literatura, que diz que os partidos no Brasil são fracos, inconsistentes e pouco disciplinados na arena legislativa, encontra correspondência na câmara alta ou se, como mostra outra corrente, os partidos apresentam convergência interna e os parlamentares votam disciplinadamente.

Dessa forma, pretendo contribuir para preencher uma lacuna deixada pela ciência política, que se debruçou fortemente sobre a câmara baixa nas duas últimas décadas. Dado o avançado grau de conhecimento que temos da Câmara dos Deputados, não é exagero dizer que os estudos sobre o Senado estão apenas "engatinhando". Embora a produção acadêmica sobre a Instituição tenha aumentado nos últimos anos - um bom exemplo disso é o livro organizado por Leany Lemos em 2008 análises sobre as votações nela realizadas são raras, com as exceções de Desposato, 2006, e Branco, 2008.

Em parte, a carência de estudos sobre a Casa é explicada pela dificuldade na obtenção de dados. Enquanto a Câmara dos Deputados disponibiliza em meio eletrônico todas as suas votações, no Senado só é possível obtê-las por meio de consultas aos seus diários. As informações referentes ao período posterior a julho de 1997 podem ser realizadas por acesso à página do Senado na internet; antes disso, somente por meio de consulta em seu arquivo físico em Brasília, que deve ser feita página por página.

As votações nominais não dizem tudo sobre o comportamento de um Legislativo, mas elas nos fornecem informações cruciais. A disciplina é um importante indicador da força dos partidos, de como eles funcionam, de como interagem com o Poder Executivo e se os governos podem agir de forma decisiva ou se precisa obter suporte para cada votação. A indisciplina torna os partidos menos previsíveis e menos estáveis, podendo custar a sobrevivência do governo nos sistemas parlamentaristas e torná-lo muito instável nos sistemas presidencialistas.

Não obstante, a análise de tais votações tem sofrido diversas críticas. Alguns autores afirmam que elas estão sujeitas a viés de seleção, já que 
só são analisadas aquelas em que os parlamentares se manifestam abertamente (Carrubba et alii, 2006). Outros sugerem que a convergência de votos dos deputados de um mesmo partido deve ser vista como uma decorrência de posicionamento ideológico, de preferências similares, da similitude de interesses de seus eleitores e não de atitude disciplinada em relação aos líderes (Cintra, 2004; Ames, 2003; Cox e McCubbins, 1993). A discussão tem a ver com o debate sobre disciplina e coesão. Esta última diz respeito à similaridade de preferências entre os membros do grupo, da capacidade de trabalharem juntos para obterem os seus objetivos. Já a disciplina é definida por Tsebelis (1995:311) como "a capacidade que o partido tem para controlar os votos de seus membros no parlamento". Segundo Giannetti e Laver (2008), ela é o "resultado de um jogo estratégico realizado dentro do partido, em que os liderados respondem a recompensas e punições".

Uma terceira crítica que se levanta contra a análise de votações nominais é de que ela não considera as chamadas "reação antecipada" e "não decisão" (Ames, 2003). O argumento é de que a disciplina (e o alto índice de aprovação das propostas governamentais) pode ser alta porque o Executivo deixa de encaminhar as matérias que correm risco de serem derrotadas. O mesmo raciocínio vale para o posicionamento dos líderes partidários, que liberariam suas bancadas nas matérias que exibem um alto grau de conflito interno. Embora tal crítica deva ser levada em consideração, os autores que a fazem não apresentam a solução e não explicam por que, em determinados momentos e situações, a disciplina é baixa. Sendo o presidente e os líderes partidários atores bem informados e com grande capacidade de agendamento, era de se esperar que eles reagissem antecipadamente em todas as matérias. Nesse caso, não haveria votações com baixa disciplina, o que não é o caso.

Outra crítica possível é de que os índices de disciplina geralmente são tomados como elevados, sem que se tenha uma referência de comparação. Em nível internacional, duas respostas a ela foram dadas por Carey (2007) e Morgenstern (2004), que analisam o comportamento dos partidos em dezesseis e cinco países, respectivamente, sob diferentes arranjos institucionais. No Brasil, cabe registrar a comparação que fizeram Limongi e Figueiredo (1998) e Santos (2002) dos dois períodos democráticos vivenciados pelo país, sob condições macroinstitucionais semelhantes: presidencialismo, multipartidarismo, federalismo, e eleição proporcional de lista não ordenada. Dessa forma, os autores brasileiros puderam perceber que a resposta para as diferenças encon- 
tradas estavam nas instituições "microinstitucionais", isto é, nas regras internas de funcionamento do Legislativo, principalmente nas suas implicações para o relacionamento com o Executivo.

Porém, todos os estudos citados centraram o foco sobre o funcionamento da câmara baixa, exclusivamente. Quase nada se sabe sobre o que acontece no Senado. A comparação entre os partidos nas duas Casas legislativas, no mesmo momento, permite que se mantenham constantes as instituições "macroinstitucionais", sem perder o controle das mudanças que o país sofreu durante esse hiato histórico, que não foram pequenas. Dessa forma, torna-se possível avaliar até que ponto as "microinstituições" são, de fato, responsáveis pelos resultados encontrados até então. Entre outras, pretendo responder às seguintes perguntas: o grau de disciplina / coesão (ou unidade) partidária no Senado assemelha-se ao que se verifica na Câmara? Em caso afirmativo, quais são os fatores decisivos para esse comportamento? Seriam os mesmos que explicam a situação na câmara baixa? Até que ponto os poderes legislativos do presidente e o grau de centralização do processo decisório no Senado respondem pelo comportamento dos senadores?

Dado que não se conhece quase nada sobre as votações nominais no Senado, a minha preocupação principal é a de fazer uma descrição geral dos dados e verificar como os partidos se comportam, mais especificamente no que diz respeito à sua unidade interna, isto é, ao grau em que votam unidos no plenário. Paralelamente, busco avaliar quais são as características institucionais que influenciam esse comportamento. A análise está sendo feita sempre em comparação com a Câmara dos Deputados. Para saber se a disciplina é alta ou baixa, não há referencial melhor do que a câmara baixa, que já conhecemos relativamente bem. Na seção que se segue, faço uma retrospectiva sobre a discussão do sistema partidário brasileiro e suas implicações para o relacionamento entre o Legislativo e o Executivo, procurando incluir o Senado nesse debate. Na seção três, apresento os dados utilizados e discuto alguns aspectos metodológicos, incluindo a preocupação com a possibilidade de viés, por incluir partidos pequenos e pouco coesos/disciplinados no estudo. Em seguida, na seção quatro, procedo à análise dos dados propriamente dita, adotando tanto uma perspectiva cross-section quanto temporal. Na seção cinco, busco discutir por que, a despeito da grande diferença entre as duas Casas, os resultados são parecidos. Por fim, 
apresento as conclusões, fazendo algumas considerações finais e sinalizando pesquisas futuras.

\section{SISTEMAS PARTIDÁRIO E ELEITORAL E AS PECULIARIDADES DO SENADO}

Parte expressiva da literatura em ciência política classifica o sistema partidário brasileiro como pouco institucionalizado, altamente fragmentado, composto por políticos motivados por interesses paroquiais e clientelistas, e desfocados das questões nacionais (Ames, 1995; Lamounier e Meneguello, 1986; Lima Júnior, 1993; Mainwaring, 1991, 2001; Mainwaring e Scully, 1995). Segundo Mainwaring (1991: 354-355), "considerando o nível de desenvolvimento econômico do país, o Brasil pode ser um caso único de subdesenvolvimento partidário no mundo [...]. Na América Latina, todos os países razoavelmente desenvolvidos tiveram mais estabilidade partidária". Na opinião de Sartori (1993:11), "seria difícil encontrar um país que fosse tão antipartidário quanto o Brasil, tanto na teoria quanto na prática [...] os políticos mudam de partido livre e frequentemente, votam em desacordo com sua orientação e recusam-se a aceitar qualquer tipo de disciplina partidária”. Para Ames (2003:102), “o Brasil tem organizações partidárias muito fortes nos planos municipal e estadual, mas quase não se pode falar em partidos políticos no âmbito nacional".

Segundo esses autores, o problema decorre da adoção do sistema presidencialista, do arranjo federativo e, principalmente, do sistema eleitoral. Características como a figura do "candidato nato" e o voto de lista aberta induzem o voto no indivíduo, e não no partido, e acirram a disputa entre candidatos da mesma legenda. Nesse contexto, os líderes partidários ficam privados da função de definir a posição dos candidatos na lista eleitoral e perdem instrumento importante de controle sobre a eleição do parlamentar. Consequentemente, os legisladores eleitos tornam-se individualistas e autônomos, enfraquecendo os líderes e gerando indisciplina partidária na arena legislativa.

Todavia, há autores que argumentam em sentido contrário. Baseados em dados sobre votações nominais. Figueiredo e Limongi $(1995,1999)$ apresentam evidências que contrariam fortemente a crença prevalecente a respeito do funcionamento do Legislativo no Brasil. Os dois autores verificam que o sistema partidário possui uma organização bem mais estruturada do que supõe a literatura: os partidos apresentam disciplina interna expressiva, é possível alinhá-los em um continuum 
ideológico, o comportamento dos parlamentares em plenário é previsível e as crenças relacionadas ao predomínio de uma dinâmica federativa no sistema não se justificam. Segundo Figueiredo e Limongi, as maiorias no Legislativo são formadas com base em um governo de coalizão, operacionalizada pelo presidente e os líderes partidários, e não individualmente, com cada deputado. Outros autores chegaram a conclusões semelhantes (Nicolau, 2000; Lyne, 2005; Meneguello, 1998:72; Santos, 1997; Pereira e Mueller, 2004).

De acordo com Figueiredo e Limongi (1995; 1999; 2008), dois fatores são fundamentais para garantir a disciplina dos partidos e, consequentemente, a influência do Poder Executivo sobre as decisões que são tomadas na Câmara dos Deputados. O primeiro deles refere-se aos poderes institucionais do presidente, tais como a possibilidade de editar medidas provisórias, solicitar urgência para suas matérias, vetar projetos de lei e propor matérias legislativas. O segundo diz respeito às regras centralizadoras do processo legislativo na Câmara dos Deputados, que colocam nas mãos dos líderes partidários o controle da agenda dos trabalhos, restringindo o campo aberto às estratégias individualistas dos congressistas. Do ponto de vista dos deputados, a agregação em torno do partido seria a forma de viabilizarem a sua ação coletiva e aumentarem seu poder de barganha junto ao Executivo federal, já que, individualmente, não teriam como arrancar suas concessões (Figueiredo e Limongi, 1999:34-35; Carey e Reinhardt, 2003:779; Santos, 2003:110). Outra consideração possível está relacionada ao fato de que os legisladores operam em condições de baixa informação, de incerteza e de sobrecarga de trabalhos, o que faz com que eles busquem nos líderes partidários uma referência para seus votos. Consequentemente, o plenário da Casa acaba apresentando alto grau de consistência e de estruturação ideológica, e o comportamento dos partidos passa a ser altamente previsível.

Um problema com o trabalho desses autores - de ambas as correntes -é que eles se voltam para a câmara baixa com exclusividade, embora frequentemente expandam suas conclusões para todo o Poder Legislativo. Desconsideram que existe outra Casa, tão importante quanto a primeira, cuja concordância é necessária para que uma matéria legislativa seja efetivamente aprovada. O objetivo principal desse artigo é trazer essa discussão para o Senado, procurando verificar se, a exemplo do que acontece na Câmara, os partidos são disciplinados e/ou coesos, e levantar hipóteses que expliquem os resultados. 
Apesar das divergências, os autores concordam que o presidente tem amplos poderes para interferir no processo legislativo e que o Congresso funciona de forma centralizada. A partir desses achados originais de Figueiredo e Limongi, seria de se esperar um comportamento mais partidário também na câmara alta. Segundo os dois autores, "os regimentos internos da Câmara e do Senado conferem amplos poderes aos líderes partidários para agir em nome dos interesses do seu partido [...]. Mais do que isso, reconhecem formalmente a existência do colégio de líderes" (Figueiredo e Limongi, 1999:28). Em outra passagem, os autores afirmam que as normas do regimento interno do Congresso permitem que "os líderes partidários controlem a agenda de trabalho e restrinjam o espaço para as estratégias individualistas dos deputados e senadores" (idem, 1995:500). De fato, em diversas situações, os líderes podem responder por suas bancadas e dispõem de importantes poderes de agenda. Eles definem os temas substantivos, estruturam a pauta dos trabalhos, agilizam o processo legislativo e reduzem a incerteza de uma negociação descentralizada. Até mesmo autores que se opõem a essa corrente reconhecem a importância desse grupo na estruturação dos trabalhos legislativos.

Figueiredo e Limongi deram uma contribuição ímpar para o entendimento de como funciona a Câmara dos Deputados no Brasil e seu relacionamento com o Poder Executivo. No entanto, temos razões para acreditar que os resultados sejam diferentes no Senado. As suas regras internas não são as mesmas, o capital político dos senadores tende a ser maior e o poder de agenda do Executivo parece menor.

Vejamos o caso da solicitação do regime de urgência, por exemplo, que promove uma interferência substancial no processo legislativo. A urgência dispensa exigências e formalidades regimentais, reduzindo o tempo de tramitação de uma matéria e aumentando as suas chances de aprovação. Quando solicitada pelo presidente da República, obriga que cada uma das Casas se manifeste em até 45 dias. Quando solicitada pelo Legislativo, faz com que a matéria entre em discussão na sessão imediata, passando a ocupar o primeiro lugar na ordem do dia. Na prática, é o que acontece na maioria das vezes, pois o Poder Executivo pode usar a sua base de sustentação para solicitá-la. Isso acontece nas duas Casas legislativas, mas na Câmara parece ser operacionalizada mais facilmente. Em primeiro lugar, porque é necessário apenas um terço dos parlamentares, contra dois terços no Senado. Em segundo lugar, porque esses números podem ser substituídos pelos votos dos respec- 
tivos líderes partidários, o que parece ser mais fácil na primeira, dada a existência formal do Colégio de Líderes ${ }^{1}$.

O conceito de disciplina partidária envolve o comando de um líder (e a sua aceitação), o qual deve ter os meios de fazer com que os desertores sejam punidos. É importante, portanto, avaliar os recursos e as condições que ele tem para conseguir a obediência de seus liderados, inclusive no que diz respeito ao seu capital político. No caso do Senado, deve-se considerar que se trata de uma "casa de elite", onde quase não existe o chamado "baixo clero". Com exceção dos suplentes, quase metade dos senadores já haviam ocupado cargos considerados superiores, tais como os de ministro, governador, presidente e vice-presidente da República ${ }^{2}$. Apenas 33\% deles tornaram-se também líderes partidários no Senado ${ }^{3}$. Nesse contexto, a capacidade de os líderes imporem a sua vontade fica reduzida. De fato, quem conhece minimamente a política brasileira custa a acreditar que tem ou tenha havido relação de liderança de Renan Calheiros sobre José Sarney e Pedro Simon, por exemplo; de Ideli Salvati sobre Eduardo Suplicy e Aloizio Mercadante; de José Agripino sobre Antônio Carlos Magalhães e Marco Maciel; de Sérgio Machado sobre José Serra, só para citar alguns. Para se destacar no Senado, o parlamentar não precisa necessariamente ocupar postos formais de direção ou de liderança; a sua influência na Casa é determinada pela sua história política anterior ao mandato.

Outro fator que supostamente fortalece os líderes é a prerrogativa que eles têm de indicar os membros de seus partidos para as comissões (Santos, 2003; Cox e McCubbins, 1993). Conhecemos pouco sobre as comissões da nossa câmara baixa e, menos ainda, da câmara alta. Sabe-se que elas não contam com a força que têm no Congresso norte-americano, cujas pesquisas serviram de referência para os estudos do Legislativo no Brasil. Não obstante, é possível fazer algumas reflexões baseadas nas diferenças entre as duas Casas. Dado o número bem menor de senadores, a chance de eles participarem de um número maior de comissões é bem mais elevada, ainda que a Câmara dos Deputados tenha quase o dobro do número de comissões encontradas no Senado (vinte e onze, respectivamente). De acordo com o regimento da primeira, um deputado deve participar, no máximo, de uma comissão permanente; no Senado, esse número sobe para três. Sendo assim, a possibilidade de um senador fazer parte de uma ou mais comissões de seu interesse, ou de nelas ocupar cargos importantes, aumenta consideravelmente em relação a um deputado. Conclui-se, portanto, que os líderes no Se- 
nado têm menos possibilidades de escolha e menor poder de barganha em relação aos seus liderados - consequentemente, menor capacidade de obter disciplina - vis-à-vis os líderes na câmara baixa.

Portanto, diante das limitações institucionais e dos constrangimentos pessoais a que os líderes estão submetidos em relação aos seus liderados no Senado, espera-se que os senadores sejam substancialmente menos disciplinados que os deputados, que apresentem um comportamento mais individual e menos partidário. Antes de verificar se isto acontece de fato, apresento, a seguir, algumas considerações sobre os dados que estou utilizando e a forma como eles estão sendo tratados.

\section{DESCRIÇÃO DOS DADOS E ASPECTOS METODOLÓGICOS}

A análise será feita exclusivamente com as votações nominais, isto é, aquelas em que os votos dos senadores e deputados são registrados e divulgados publicamente. Elas podem acontecer em duas situações: em matérias que exigem maioria qualificada para sua aprovação (emendas constitucionais, leis complementares, pedidos de urgência urgentíssima); e quando for requerida a verificação de quórum de uma votação simbólica, com o apoio de três senadores. Em geral, essa solicitação é feita no intuito de reverter uma decisão já tomada ou de aumentar os custos políticos para os adversários, fazendo com que os seus votos sejam declarados publicamente.

Serão cobertos os 21 anos posteriores à promulgação da Constituição (1989-2009), abrangendo seis legislaturas e o mandato de cinco presidentes diferentes. Nesse período, foram encontradas 2.307 votações na Câmara e 1.381 no Senado. Em parte, a diferença entre as duas Casas pode ser explicada pela prerrogativa constitucional que define a câmara baixa como iniciadora dos projetos de lei propostos pelo Presidente da República, pelo Supremo Tribunal Federal e pelos tribunais superiores.

A análise centrará o foco sobre os partidos minimamente expressivos. Embora 29 legendas tenham sido representadas na Casa entre 1989 e 2009 (com senadores titulares e/ou suplentes), incluí apenas as que participaram em, pelo menos, $1 \%$ das votações nesse período. Juntos, elas somaram nada menos que $94,1 \%$ do total.

Para avaliar a disciplina / coesão partidária, recorrerei ao tradicional índice de Rice, que tem sido amplamente utilizado em estudos na área, 
desde que foi apresentado pelo seu criador (Rice, 1924). Trata-se de um índice flexível, intuitivo e facilmente interpretável, que é calculado como sendo a diferença (em valores absolutos) entre o percentual de votos "sim" e o percentual de votos "não". O índice pode variar de zero (quando metade votou "sim" e a outra metade votou "não") a 1 (quando todos votaram da mesma forma). O cálculo da coesão foi realizado para cada um dos partidos, em cada uma das votações, sendo o resultado final a média geral desses resultados parciais.

O índice de Rice apresenta o inconveniente de considerar apenas os indivíduos que votaram, deixando de fora os ausentes, os que se abstiveram e os que obstruíram. No intuito de contornar o problema, os pesquisadores que estudam a Câmara dos Deputados usam como referência a indicação de voto dos respectivos líderes partidários, feita verbalmente em plenário antes de cada uma das votações. Em geral, consideram que a ausência, a abstenção e a obstrução é uma tomada de posição indisciplinada por parte do parlamentar, quando o líder está indicando um voto favorável ou contrário à matéria que está sendo votada. No entanto, a indicação de liderança no Senado é uma prática muito menos frequente do que na Câmara ${ }^{4}$; para usar o mesmo procedimento na análise do primeiro, eu teria que abrir mão de mais da metade das votações que estão no banco de dados.

Essa diferença entre as duas Casas parece importante e diversas explicações podem ser levantadas. Pode ter a ver com o fato de o Senado contar com apenas 81 membros, o que lhe permite funcionar com informalidade e fluidez. Para que os líderes sugiram aos seus liderados como devem votar, basta um gesto ou um simples "olhar". Outra justificativa vem dos próprios regimentos internos: o da câmara baixa diz que "[...] cada líder poderá manifestar-se para orientar sua bancada, pelo tempo não excedente a um minuto"; já o do Senado determina que os líderes votarão em primeiro lugar, seguidos pelos demais senadores $^{5}$. Ela pode também ser uma evidência de que o comportamento dos senadores é mais guiado pela coesão entre eles do que pela disciplina imposta pelos lideres.

Um problema que é frequentemente lembrado em estudos de disciplina partidária é que as votações são analisadas em conjunto, mas não apresentam o mesmo grau de controvérsia. Variam de acordo com os temas que estão sendo analisados (Bond e Fleischer, 1990:70; Olson e Mezey, 1991:210; Carey, 1999; Mainwaring e Perez-Liñan, 1997; 
Figueiredo e Limongi, 1995). Muitos votos são tomados em matérias consensuais, os quais não geram grande oposição. No intuito de contornar o problema, os autores utilizam diferentes recortes e estratégias em suas amostras. Nos Estados Unidos, Cox e MacCubbins (1993) definem um voto de liderança como sendo aquele em que a liderança do Partido Republicano opõe-se à do Partido Democrata. Para um contexto multipartidário, Lyne (2005) recomenda que se avaliem apenas as votações em que todos os partidos da coalizão fazem a mesma recomendação de voto, enquanto os partidos de oposição fazem a recomendação contrária. Carey (1999) considera, simultaneamente, as informações sobre quão apertada foi a votação e sobre a taxa de comparecimento dos deputados. Mainwaring e Perez-Liñan (1997) calculam o percentual de vezes que um legislador votou com a maioria do seu partido em votações altamente contestadas, isto é, aquelas em que um mínimo de $25 \%$ dos legisladores presentes votam contra o vencedor.

Obviamente, o ponto de corte escolhido pode fazer diferença para os resultados. Nada obstante, não existe consenso sobre qual seria o ponto ideal. Nessa pesquisa, foram excluídas da análise as votações que apresentaram menos de $10 \%$ de discordância, patamar que tem sido utilizado por pesquisadores que analisaram a Câmara dos Deputados no Brasil (Amorim Neto e Santos, 2001; Figueiredo e Limongi, 1999; Nicolau, 2000). Penso que esse seria um ponto de corte suficiente, tendo em vistaque as matérias que são decididas em votações nominais já envolvem algum grau de conflito.

Isso fez com que as populações de 1.381 votações no Senado e de 2.307 na Câmara fossem reduzidas para amostras de 646 (46,8\%) e 1.771 $(76,8 \%)$, respectivamente. Trata-se de outra diferença importante entre as duas Casas legislativas. Ela mostra que o Senado conta com uma proporção de votações unânimes bem maior do que a Câmara. Uma possível explicação para essa situação pode ser creditada ao fato de que a maioria das matérias legislativas inicia-se pela Câmara dos Deputados, chegando ao Senado com um grau maior de consenso. Outro fato que ajuda a explicá-la é que as votações relacionadas à concessão de canais de rádio e televisão costumavam ser realizadas por votação nominal no Senado, sendo quase sempre aprovadas sem nenhum voto contrário. Nada menos que 321 votações nominais realizadas naquela Assembleia no período analisado tratavam desse tipo de matéria legislativa. Parecem ser assuntos de alto interesse dos senadores e que en- 
volve intensa troca de votos, conhecida na literatura como "log-rot ling" 6 .

Apesar de serem amplamente utilizadas nos estudos legislativos, Desposato $(2003 ; 2005)$ alerta que medidas de coesão tendem a ser infladas e estão sujeitas a sério viés, podendo criar a ilusão de unidade no grupo, quando ela não existe. De acordo com o autor, o risco é ainda maior quando se analisa grupos pequenos e pouco coesos. Em um sistema partidário fragmentado como o brasileiro, com grande variação no tamanho e no grau de coesão dos partidos, a cautela deve ser maior. Mais ainda no Senado, uma Casa legislativa relativamente pequena, onde os partidos são ainda menores. Nesse contexto, avisa o autor, o risco de que os resultados reflitam as propriedades do índice, e não o fenômeno político que está sendo estudado, é alto.

Para resolver o problema, Desposato propõe um método simples e flexível: reduzir artificialmente o tamanho dos partidos grandes, substituindo o seu valor de coesão pelo valor esperado, de forma que possam ser comparados com os partidos pequenos em uma mesma métrica. Basicamente, consiste em definir pesos diferentes para cada um deles, na equação que calcula o índice de coesão. Dessa forma, pode-se evitar, por exemplo, que um partido grande como o Partido do Movimento Democrático Brasileiro (PMDB) seja analisado com a mesma medida que uma legenda pequena como o Partido Progressista Renovador (PPR). Ou que a bancada de deputados do Estado de Rondônia conte da mesma forma que a bancada do Estado de São Paulo.

A partir da proposta de Desposato (2005:738), o índice de Rice foi corrigido por meio do cálculo da probabilidade de que dois membros do partido " $\mathrm{i}$ ", selecionados aleatoriamente, votem juntos no projeto " $\mathrm{j}$ ", que pode ser expressa pela seguinte fórmula:

$$
E\left(C_{i j 2} \mid Y, R\right)=\frac{Y(Y-1)+(R-Y)(R-Y-1)}{R(R-1)}
$$

Onde $\mathrm{C}=$ ao índice de coesão, $\mathrm{R}=$ tamanho do partido e $\mathrm{Y}=$ número de votos "sim". Se o índice já for conhecido, a fórmula pode ser reduzida a:

$$
E\left(C_{2} \mid Y, R\right)=\frac{R C^{2}+R+2}{2(R-1)}
$$




\section{ANÁLISE DOS DADOS}

Inicio a análise comparando o tamanho dos partidos nas duas Casas legislativas, medido pelo percentual de votos que deram no plenário em todo o período analisado. Na tabela que se segue, foram incluídos apenas os dez maiores. Em conjunto, eles somaram $94,1 \%$ dos votos dados no Senado e 84,7\%, na Câmara. Vale destacar a importância do PMDB e do Partido da Frente Liberal (PFL), que foram responsáveis por mais da metade das manifestações (52\%) no primeiro, contra um pouco mais de um terço (35\%) na câmara baixa. Merece destaque também o tamanho substancialmente maior do Partido dos Trabalhadores (PT) nessa última, onde ocupou $12,7 \%$ das cadeiras, contra 8,4\% no Senado. Esses resultados fizeram com que o centro-direita ocupasse um espaço maior na câmara alta do que na câmara baixa. Apesar da desproporção entre as duas Assembleias ser alta em outros partidos, o tamanho bem menor do Senado fez com que a situação geral não mudasse substantivamente.

Tabela 1

Tamanho dos Partidos, Medido pelo Percentual de Votos Dados em Plenário (1989-2009)

\begin{tabular}{l|c|c|c}
\hline Partido & Senado & Câmara & Diferença \\
\hline PMDB & $28,4 \%$ & $18,8 \%$ & $+9,6$ \\
PFL/DEM & $23,8 \%$ & $16,2 \%$ & $+7,6$ \\
PSDB & $16,0 \%$ & $14,4 \%$ & $+1,6$ \\
PT & $8,4 \%$ & $12,7 \%$ & $-4,3$ \\
PTB & $5,1 \%$ & $5,7 \%$ & $-0,6$ \\
PDT & $4,4 \%$ & $4,9 \%$ & $-0,5$ \\
PPB & $2,8 \%$ & $6,3 \%$ & $-3,5$ \\
PSB & $2,7 \%$ & $3,2 \%$ & $-0,5$ \\
PPS & $1,3 \%$ & $1,7 \%$ & $-0,4$ \\
PPR & $1,2 \%$ & $0,8 \%$ & $+0,4$ \\
\hline Total & $\mathbf{9 4 , 1 \%}$ & $\mathbf{8 4 , 7 \%}$ & $+\mathbf{9 , 4}$ \\
\hline
\end{tabular}

Fonte: Arquivo do Senado e banco de dados legislativos do Cebrap.

Cálculos efetuados pelo autor.

Uma primeira descrição do índice de Rice (sem correção de viés) foi apresentada no Apêndice 1. Ela mostra uma média geral para o Senado $(78,5 \%)$ muito próxima da encontrada na Câmara $(81,2 \%)$, com uma diferença de apenas 2,7\%. Quando são incluídas todas as votações - isto 
é, sem o corte das unânimes - a situação inverte-se: o índice de Rice do primeiro sobe para $91,2 \%$ e o da Câmara, para $88,6 \%$.

Uma análise mais segura, que leva em consideração o fator de correção proposto por Desposato $(2003,2005)$, pode ser feita a partir da tabela que se segue. Como previsto por aquele autor, em geral, o fator de correção fez com que o nível de disciplina / coesão aumentasse, em relação aos índices não corrigidos do Apêndice 1. Ele cresceu especialmente nos partidos maiores e menos coesos. Aumentou tanto no Senado $(2,5 \%)$ quanto na Câmara (3,8\%). Ficou praticamente a mesma no PT, um partido que, no período considerado, esteve mais para médio e pequeno do que para grande.

Tabela 2

Índice de Rice (corrigido), de 1998 a 2009

\begin{tabular}{l|c|c|c}
\hline Partido & Senado & Câmara & Diferença \\
\hline PMDB & 75,8 & 78,6 & $-2,8$ \\
PFL/DEM & 81,4 & 84,9 & $-3,5$ \\
PSDB & 81,7 & 86,0 & $-4,3$ \\
PT & 90,5 & 96,6 & $-6,1$ \\
PTB & 76,7 & 81,5 & $-4,8$ \\
PDT & 79,7 & 87,3 & $-7,6$ \\
PPB & 77,0 & 78,6 & $-1,5$ \\
PSB & 87,7 & 88,3 & 0,5 \\
PPS & 89,4 & 84,1 & $+5,3$ \\
PPR & 75,5 & 80,4 & $-4,9$ \\
\hline Geral & $\mathbf{8 1 , 0}$ & $\mathbf{8 5 , 0}$ & $\mathbf{- 4 , 0}$ \\
\hline
\end{tabular}

Fonte: Arquivo do Senado e banco de dados legislativos do Cebrap.

Cálculos efetuados pelo autor.

Os resultados acima mostram que a disciplina/coesão partidária não está relacionada ao tamanho do partido. Encontramos níveis altos tanto em partido grande (PFL/Democratas - DEM), quanto em partidos médios (Partido da Social Democracia Brasileira - PSDB e PT) e pequenos (Partido Popular Socialista - PPS e Partido Socialista Brasileiro PSB). Índices baixos são encontrados tanto em partido grande (PMDB) quanto em pequeno (PPR). Não parecem tampouco estarem relacionados ao posicionamento ideológico. Ao centro do espectro político, há partidos mais e menos disciplinados (PSDB e PMDB, respectivamen- 
te). Na direita, o PFL/DEM apresenta índices mais altos, e o Partido Progressista Brasileiro (PPB) e o PPR, mais baixos.

A interpretação mais importante para o meu propósito aqui diz respeito à diferença entre as duas Casas. Ao se tirar a média geral de todas as votações e de todos os partidos, chega-se a $81 \%$ no Senado e a $85 \%$ na Câmara. A interpretação adequada desses resultados depende do que se entende por um partido disciplinado ou coeso. Afinal, a diferença encontrada entre Câmara e Senado é suficiente para dizer que os partidos apresentam um comportamento diferente em cada uma delas? Uma diferença de $4 \%$ no índice de Rice é suficiente para dizermos que os partidos na Câmara são disciplinados e no Senado não são? Será que o fato de o PMDB sair de um índice de Rice $75,8 \%$ para $78,6 \%$ o transforma de um partido indisciplinado em disciplinado? Ou que o PFL/DEM no Senado é um partido muito diferente do PFL/DEM na Câmara, por conta de um aumento de 3,5\% no referido índice? Na minha percepção, a resposta para tais perguntas é negativa. Uma resposta positiva nos obrigaria a reconhecer que o PSDB é um partido disciplinado e que o PPB e o Partido Trabalhista Brasileiro (PTB) não o são, já que a diferença entre eles na Câmara chega a 7,4\% e 4,5\%, respectivamente.

Sendo assim, para avançar no debate, estou admitindo que eles são disciplinados (ou coesos, se preferirem) em ambas as câmaras legislativas. A despeito de ser menor no Senado, considero que a distinção em termos de disciplina/coesão não é substancialmente expressiva, ao ponto de mudar a concepção que tem prevalecido com relação ao que acontece na Câmara dos Deputados. Em uma votação qualquer, a probabilidade de um senador votar da mesma forma que o líder do seu partido é de $87,7 \%$. Esse patamar está muito próximo do que foi identificado por Figueiredo e Limongi (1999:27) para a câmara baixa, que foi de $89,4 \%$. A exemplo do que os dois autores encontraram na primeira Casa, os partidos no Senado também não parecem ser pouco institucionalizados, inconsistentes, erráticos e com alto grau de indisciplina. Ainda que a disciplina / coesão seja menor em alguns partidos de centro e de direita - especialmente PMDB e PPB - ela é alta em todo o espectro ideológico.

Uma avaliação ao longo do tempo pode dar uma ideia mais clara sobre a diferença entre as duas Casas legislativas. Para isso, nada melhor do que uma interpretação visual. No gráfico que se segue, apresento a tra- 
Gráfico 1

Índice de Rice Corrigido

(1989 a 2009)
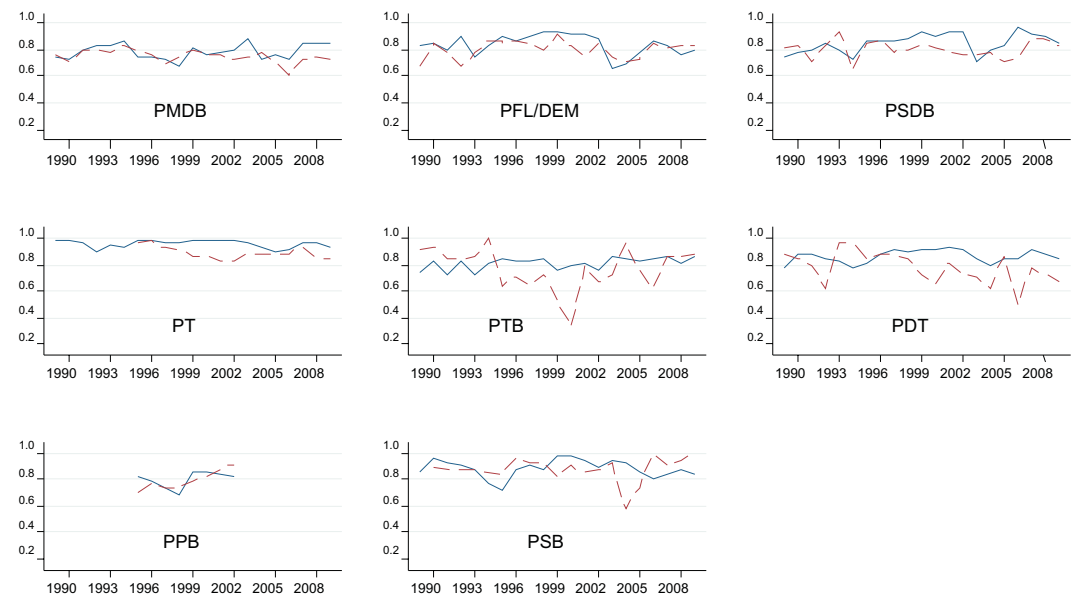

\section{Câmara ........ Senado}

jetória do índice de Rice (corrigido) nos partidos que contaram com, no mínimo, dois representantes no Senado ao longo de oito anos, pelo menos.

O gráfico confirma a estatística descritiva: em geral, a disciplina partidária foi alta durante o período analisado, em ambas as Assembleias, sendo levemente menor no Senado. Embora a diferença entre elas seja visivelmente maior no PTB e no PDT, é preciso lembrar que os dois partidos, juntos, responderam por apenas $9,5 \%$ dos votos dados no plenário do Senado entre os anos de 1989 e 2009. É preciso evitar, portanto, que o impacto visual desses dois partidos contamine a análise geral. Um peso mais expressivo deve ser dado aos quatro primeiros partidos (PMDB, PFL/DEM, PSDB, PT), que responderam por $77 \%$ dos votos dados na câmara alta. No caso deles, o índice permaneceu alto e relativamente estável nas duas Casas, frequentemente acima de $80 \%$. No PT, ficou quase sempre acima de $90 \%$, o que sugere a confirmação da hipótese de Duverger (1954) e de MacRae (1967:55-57) de que os partidos de esquerda são mais disciplinados.

Portanto, a partir desses dados, não podemos dizer que os partidos são instáveis, voláteis, inconstantes ou ideologicamente frágeis. A despei- 
to de algumas oscilações no PFL/DEM e no PSDB, os partidos maiores mantiveram razoável grau de unidade ao longo do tempo. E isso aconteceu em um período em que diversos presidentes, com diferentes inclinações ideológicas, exerceram o poder: sete, se contarmos a transição dos presidentes Fernando Henrique e Lula para o segundo mandato como tal. Caso os parlamentares fossem movidos por motivações predominantemente clientelistas, era de se esperar divisão interna maior nos partidos, especialmente daqueles que não fazem parte da coalizão de governo.

Alguém pode dizer que níveis de disciplina em torno de $80 \%$ não são altos, ou que para se fazer tal afirmação seria necessário fazer uma comparação com legislativos de outros países. Essa é uma discussão antiga dos estudos legislativos no Brasil, que eu não tenho a pretensão de esgotá-la aqui. O meu objetivo nessa pesquisa é tão somente verificar o que acontece no Senado. O ponto que estou defendendo é que, se admitirmos que existe disciplina na Câmara - como faz a maioria da literatura na área - não podemos dizer que aconteça diferente no Senado. De fato, ela é um pouco menor nesse último, mas não o suficiente para se chegar a uma conclusão inovadora.

Existe uma diferença entre a Câmara e o Senado no que se refere ao grau de unidade partidária, mas ela não parece ser substantivamente expressiva. Mais importante é a diferença que aparece dentro de cada uma das Casas. A distância em termos de disciplina/coesão entre o PFL/DEM do Senado e o PFL/DEM da Câmara, por exemplo, é bem menor do que a distância que o mesmo partido se encontra de vários outros na mesma Instituição. PT e PMDB estão muito mais distantes um do outro (em qualquer uma das Assembleias) do que do seu congênere na outra Casa: a diferença entre os índices de Rice (corrigidos) dos dois partidos é de $18 \%$ na primeira Câmara e de 13,5\% na segunda. No entanto, a diferença do PMDB da Câmara para o PMDB do Senado é de apenas 2,8\%. Em síntese, o que estou querendo dizer é que os partidos diferem mais um dos outros do que deles mesmos nas duas Casas.

Ainda olhando para as diferenças existentes dentro de cada uma das Assembleias legislativas, pode-se verificar que seus índices de Rice diferem também quanto ao grau de oscilação ao longo do tempo. Isso é especialmente evidente no Senado: o Gráfico 1 mostra que ela é muito maior no PTB e no PDT do que no PT e no $\mathrm{PMDB}^{7}$. Nesse contexto, não parece adequado falar em uma característica do sistema partidário 
como um todo; além de divergirem muito entre si no que diz respeito à ideologia, à composição social, ao tamanho, os partidos divergem também no grau de unidade interna, seja em uma análise cross-section, seja temporal. Conforme já apontaram Melo (2004) e Nicolau (2000), a grande variação parece ser o ponto mais marcante do sistema partidário. A inclusão do Senado nessa análise só aumenta essa diversidade, não porque o nível de disciplina/coesão difira substancialmente do que acontece na primeira câmara, mas porque os partidos lá também são muito diferentes entre si.

\section{DISCUTINDO 0 PARADOXO}

Apesar de a preocupação principal desse texto ser a de identificar o grau de disciplina / coesão dos partidos no Senado, é importante tentar descobrir os elementos que a garantem. Figueiredo e Limongi (1999) deram uma contribuição fundamental para o seu entendimento: basicamente, ela decorreria dos poderes legislativos do presidente e da forma centralizada como as decisões são tomadas no plenário, em torno do Colégio de Líderes. Mas ela explica tão somente o que acontece na câmara baixa. No Senado, as decisões parecem ser menos centralizadas, os líderes têm menos força e o Colégio de Líderes não é formalizado. Tudo isto nos leva a pensar que a disciplina seria substancialmente menor. Não foi o que aconteceu. Os dados mostram que a disciplina / coesão no Senado é pouco menor do que a que identificamos na Câmara. Como resolver esse paradoxo? Como um estudo inicial sobre disciplina no Senado, talvez ainda não seja possível solucioná-lo completamente aqui. No entanto, nada impede que sejam apresentadas algumas sugestões.

Embora o bicameralismo brasileiro seja congruente - com poderes legislativos equivalentes entre câmara baixa e câmara alta - esta última conta com diversas características distintas da primeira, que devem influenciar no seu funcionamento. Uma das mais importantes é o seu o tamanho pequeno: uma das menores do mundo, proporcionalmente à câmara baixa, com apenas $16 \%$ do seu número de membros. Consequentemente, os partidos também são pequenos, o que faz com que sejam mais homogêneos e que tenham uma estrutura organizacional menos complexa, aumentado o grau de participação de seus membros e a sua coesão interna (Michels, 1962). 
Permite, também, que a interação dos senadores seja feita face a face, com contato mais frequente e mais intenso do que o vivenciado pelos deputados, ao ponto de detectarem até mesmo as expressões faciais e o tom de voz de seus colegas de legenda. Nas palavras de Barros (2010), "os senadores têm melhores condições de socialização política, viabilizando a confecção de redes de apoio". Permite, ainda, que a influência individual seja mais expressiva, que a coordenação seja mais fácil e o controle social sobre os comportamentos desviantes, mais efetivo (Olson, 1965). Umas das consequências esperadas desse contexto é uma propensão maior para a disciplina / coesão.

Outro fator que deve contribuir para que haja disciplina no Senado é o ambiente supostamente favorável à troca de votos entre os legisladores (log-rolling) e à sustentação dos acordos. Em primeiro lugar, porque o tamanho pequeno e a duração prolongada do mandato levam a uma relação mais estreita entre os senadores, o que aumenta a confiança e a possibilidade de que os pactos serão cumpridos nas próximas votações. Em segundo lugar, entra o fato de que a renovação das comissões permanentes é feita a cada dois anos (contra um ano na Câmara), proporcionando mais tempo para realizar os acordos informais e a troca de apoio nas deliberações (Araújo, 2010). Acrescente-se a menor diversidade de atores no Senado em relação à Câmara - medida pelo número de cadeiras e de partidos - que também levaria ao mesmo efeito (Carrubba e Volden, 2000).

No caso do PMDB e do PFL - que, juntos, foram responsáveis por mais de metade dos votos dados em plenário - é possível que o fato de terem ocupado a Presidência da Casa tenha contribuído para a disciplina/coesão de seus respectivos partidos. Não se pode descartar também uma conexão entre as representações regional e partidária, dada a forte presença desses dois partidos nas regiões mais pobres e sobrerrepresentadas. Não parece ser por acaso que dos quatorze presidentes do Senado na República Nova, cinco eram provenientes do Norte, sete do Nordeste e dois do Centro-Oeste. Esse é um quadro diferente do encontrado na Câmara dos Deputados, cujos últimos quatorze presidentes tiveram a seguinte procedência: sete do Sudeste, cinco do Nordeste e dois do Sul.

Esses são dados relevantes, mas fogem do escopo deste artigo. Eles foram mencionados em função da suspeita de que o núcleo de poder no Senado esteja mais centralizado em torno do seu presidente, e não dos 
líderes partidários. Segundo Araújo (2010), além de conduzir com grande autonomia os trabalhos é ele quem define o que será discutido e votado em cada sessão e como serão conduzidas as deliberações. De acordo com o autor, diferente do que acontece na Câmara, o presidente do Senado tem mais espaço para atuar de forma discricionária, tornando-se um ator central nas negociações e um definidor de agenda praticamente indispensável ao sucesso do governo. De fato, o presidente tem poderes para incluir as matérias na ordem do dia, a seu juízo; tem autonomia para não realizar uma sessão, "por motivo de força maior", de acordo com a sua vontade; é o presidente do Congresso Nacional e quem promulga as leis, caso o presidente da República não o faça; pode propor sessão secreta e convocar sessão extraordinária, prerrogativas que, na Câmara, devem envolver o Colégio de Líderes.

Outro possível fator explicativo para a alta disciplina / coesão no Senado pode vir do fato de que a maioria das matérias tem início na Câmara dos Deputados, chegando ao Senado com menos controvérsia ${ }^{8}$. Uma evidência disso pode ser encontrada em Figueiredo e Limongi (1996), os quais verificaram que as leis provenientes da Câmara foram apreciadas no Senado em tempo bastante reduzido e apenas $18 \%$ delas foram alteradas. Eu não diria que resta a este último um papel de "casa revisora", meramente confirmatório, do que se decide na câmara baixa. A ideia é que o Senado não gasta tempo com as matérias que já foram exaustivamente discutidas e acordadas na outra $\mathrm{Casa}^{9}$, o que não significa que ele não seja decisivo quando necessário. No final, isso acabaria fazendo com que a disciplina interna dos partidos aumentasse.

Devemos considerar, ainda, que muitos senadores estão entre os mais importantes líderes nacionais e regionais de seus partidos, tendo vários deles ocupado os importantes cargos de governador, ministro e até presidente e vice-presidente da República. Em função disso, interessa a eles que seus partidos sejam disciplinados, o que só tende a fortalecê-los individualmente. A ideia é que esse grupo de elite buscaria a convergência pela via partidária como forma de manterem o importante espaço que ocupam. Sendo assim, faz pouco sentido pensar que as principais lideranças do partido não se preocupam com a unidade partidária e que tendem a votar no sentido contrário a ela.

Há uma crença estabelecida na ciência política de que o presidente tem preferências que são mais nacionais, de interesse geral e estáveis, enquanto o Congresso está preocupado com questões individuais, locais 
e paroquiais. No entanto, conforme mostram Figueiredo e Limongi (2008), não existem propriamente duas agendas em disputa: uma agenda do Executivo e outra do Legislativo. No caso específico do Senado, estudos sugerem que ele exerce um papel importante nos "assuntos de Estado", de política externa, na área econômica e de responsabilidade do presidente (Neiva, 2006, 2009; Loureiro, 2001). Na área de política fiscal, por exemplo, o Senado tem tido um papel de destaque, estabelecendo regras que aperfeiçoam o processo de controle do endividamento público (Loureiro, 2001:78). Uma explicação possível para essa situação é que boa parte dos senadores foram governadores e enfrentaram problemas orçamentários deixados por seus antecessores; estariam, por isso, mais sensíveis à definição de regras capazes de trazer a estabilização fiscal. Sendo assim, um comportamento voltado para as políticas nacionais e, portanto, partidárias, também contribuiria para o aumento da disciplina/coesão.

O nível de disciplina/coesão pode estar sendo influenciado também pela presença, não desprezível, dos senadores suplentes, que responderam por aproximadamente $20 \%$ dos votos dados no plenário do Senado no período pós-Constituinte. Segundo Neiva e Izumi (2012), eles proporcionaram um apoio maior ao governo do que os senadores titulares, comportamento esse que deve estar relacionado à disciplina em relação ao partido. Os suplentes destoam fortemente daquilo que se pode chamar de "senador ideal", um político experiente, com um forte respaldo obtido nas urnas e que foi ou será governador de seu estado. Além de não terem recebido nenhum voto, costumam ser escolhidos a partir de relações pessoais e de confiança com os senadores titulares, ou por terem sido financiadores de suas campanhas. Trata-se de indivíduos com baixo grau de informação sobre o processo legislativo ${ }^{10}$ e que não possuem qualquer compromisso com o eleitorado, ficando livres para atender aos interesses do governo e de seus respectivos partidos.

Uma vez que o Senado tem um forte caráter federativo - expresso pelo preceito constitucional de que representa os estados e pela altíssima desproporcionalidade de representação - não se pode descartar o efeito da coesão partidária no estado refletir-se na disciplina / coesão nos partidos nacionais. Acrescente-se que a fragmentação partidária em nível estadual é bem menor do que a observada na Câmara ${ }^{11}$ : como são apenas três senadores por estado, haverá, no máximo, três partidos, sendo vários os casos de dois ou de um único partido por estado. Portanto, a possibilidade que estou colocando é a de que a disciplina veri- 
ficada em nível nacional nada mais seria do que o somatório de disciplinas em nível estadual.

\section{CONCLUSÃO}

A discussão sobre a institucionalização e o grau de unidade dos partidos brasileiros foi intensa nas últimas duas décadas, mas ficou limitada à Câmara dos Deputados. Nessa pesquisa, a minha preocupação principal foi identificar como isto acontece no Senado, embora tenha frequentemente usado a primeira como referência. A conclusão geral é que o grau de disciplina/coesão partidária nas duas Assembleias não é expressivamente diferente. A exemplo do que acontece na câmara baixa, os partidos são coesos/disciplinados também na câmara alta. De agora em diante, podemos afirmar, com mais propriedade, que essa é uma característica do Legislativo, e não apenas da Câmara dos Deputados. A percepção mais evidente é de que as diferenças são maiores dentro de cada uma das câmaras legislativas do que entre elas. Os achados ajudam a refutar as teses sobre o estado caótico do sistema partidário brasileiro, com legendas voláteis e inconsistentes, que levaria a crises constantes e paralisia decisória.

Porém, as explicações não parecem ser as mesmas para as duas Casas legislativas. Na Câmara dos Deputados, os poderes legislativos do presidente da República e a centralização das decisões em torno dos líderes partidários são elementos fundamentais. No Senado, não parecem ter a mesma importância. Outros fatores devem ser buscados para justificar os resultados semelhantes. O tamanho menor, a duração maior do mandato, a renovação parcial e as suas regras internas permitem que o convívio entre os senadores seja mais próximo, permanente, fácil e fluente. A inexistência de um Colégio de Líderes formalizado, e a presença de um grupo de elite (antigos e futuros governadores e presidentes/vice-presidentes da República) fazem com que a relação entre os líderes partidários e seus liderados seja menos estruturada, menos hierárquica e mais informal. Tudo isto parece contribuir para um grau maior de unidade partidária, a despeito da ausência de uma autoridade central que defina os resultados. Nesse sentido, tal unidade parece ter mais a ver com coesão do que com disciplina.

Ao analisar o Senado dos Estados Unidos nos anos 50, Donald Matthews (1959) falava em normas não escritas (ou "folkways"), que definiam o comportamento dos senadores. Segundo o autor, tratava-se 
de um clube (grifo meu) fechado de homens, com relações de amizade e em sintonia uns com os outros, no qual a construção do consenso e a tomada de decisões ficavam facilitadas e os compromissos assumidos tendiam a ser perpetuados. Para ser respeitado, dizia Matthews, o senador devia ser cortês, evitar os desacordos e ajudar os colegas. Aqueles que não se comportavam da maneira esperada, estariam sujeitos às regras formais e a chance de aprovar os seus projetos seria reduzida. Apesar de a Instituição ter sofrido transformações (Sinclair, 1989), essa visão chama a atenção para as peculiaridades do Senado e sugere uma perspectiva diferente de análise. Essa não é uma literatura que agrade à corrente neoinstitucionalista, que predomina nas análises dos Legislativos norte-americano e brasileiros atualmente. Não obstante, acredito que ela pode contribuir para o entendimento do excepcionalismo das câmaras altas em geral, e da brasileira, em particular.

A Instituição precisa ser melhor explorada pela ciência política. No caso específico da disciplina partidária, uma análise mais apurada deve privilegiar votações com maior grau de discordância, separar as matérias por temas, por tamanho da maioria exigida para aprovação e por nível de abrangência (setorial, local, regional, nacional). É importante também controlar outras variáveis que potencialmente podem impactar a unidade interna dos partidos, tais como o tempo restante de mandato do presidente e dos parlamentares, suas características individuais, o impacto das políticas estadual e regional. Estudos comparados de votações nominais em câmaras altas de outros países também serão muito bem-vindos, já que os poucos existente são voltados para as câmaras baixas (Carey, 2007; Morgenstern, 2004).

Dada a centralidade do presidente da República no sistema político brasileiro, é oportuno também verificar o grau de apoio ao governo. A relação das arenas eleitoral e parlamentar não deve ser esquecida; a análise da dominância e da concentração dos votos recebidos pelos senadores com o seu comportamento no Legislativo apresenta-se como outra oportunidade de pesquisa. Como um dos estudos iniciais sobre votações nominais no Senado, não foi possível abranger todos esses pontos. A partir do banco de dados que acabamos de construir, essas e outras questões poderão ser melhor investigadas, formando uma agenda de pesquisa que está só começando.

(Recebido para publicação em março de 2010)

(Reapresentado em abril de 2011) (Versão definitiva em maio de 2011) 


\section{Pedro Robson Pereira Neiva}

\section{NOTAS}

1. Em $8 / 7 / 2009$, começou a tramitar no Senado o projeto de resolução $37 / 09$, de autoria do senador Aloizio Mercadante, que regulamenta o Colégio de Líderes no Senado. Para uma comparação entre os regimentos da Câmara e do Senado no que se refere às regras procedimentais, veja Ricci (2008).

2. Segundo Lemos e Ranincheski (2002), esse número não passou de $20 \%$ na Câmara dos Deputados.

3. Outra evidência da importância dos senadores vem dos números referentes à sua passagem pela Câmara dos Deputados: mais de 50\% dos titulares que tomaram posse no período de 1987 a 2010 já haviam passado por esta última. Entre os deputados, apenas 1,5\% passaram pelo Senado no período de 1987-1999 (Santos, 2000).

4. No período de 1995 a 2006, os líderes partidários deram 16.717 indicações de voto nas 1.642 matérias que foram votadas na Câmara, o que dá uma média de 10,2 por votação. No Senado, a média foi de apenas 2,5 (2.544 indicações em 1.016 votações); em muitas delas, nem mesmo os partidos maiores indicaram voto para seus integrantes.

5. Artigos 192 e 294 dos regimentos da Câmara dos Deputados e do Senado Federal, respectivamente. Agradeço a Maurício Izumi o alerta para essa diferença regimental.

6. Segundo Teixeira (2009), a proximadamente $80 \%$ dos projetos relacionados à radiodifusão foram relatados por senadores do mesmo estado das emissoras que foram regularizadas. De acordo com notícia publicada no sítio na internet Observatório da Imprensa, em 25/10/2006, 1/3 dos senadores e 10\% dos deputados da legislatura que se iniciou em 2007 possuíam concessão de emissoras de rádio ou TV. Reportagem disponível em http:/ / www.observatoriodaimprensa.com.br/artigos.asp?cod =404IPB007. Acesso em 25/5/2011.

7. Apesar de ter sido frequentemente apresentado pela imprensa como um partido volátil e altamente fragmentado, o PMDB votou de forma razoavelmente consistente e com regularidade impressionante. Com isso, manteve a sua condição de partido mediano e fundamental para o bom funcionamento de qualquer governo de coalizão no país.

8. É importante mencionar que todos os projetos do Executivo - que respondem pela maior parte dos aprovados - devem ser iniciados pela Câmara dos Deputados (conforme artigo 64 da Constituição).

9. A evidência disto é que as comissões só exercem um papel ativo para os seus próprios projetos: conforme mostra Ricci (2008:255), dos 302 projetos da Câmara sancionados no Senado entre 1991 e 2003, apenas três foram decididos terminativamente nas comissões.

10. Enquanto $54 \%$ dos senadores titulares já haviam exercido antes o cargo de deputado e $25 \%$ deles o cargo de senador, os números para os suplentes foram $13 \%$ e $3 \%$, respectivamente (Neiva e Izumi, 2012).

11. Para ilustrar essa situação, Desposato (2000:222-223) dá o exemplo da Bahia em 1994, que contava com onze partidos representados na Câmara dos Deputados e com apenas um no Senado. 


\section{Coesão e Disciplina Partidária no Senado Federal}

\section{REFERÊNCIAS BIBLIOGRÁFICAS}

AMES, Barry. (1995), “Electoral Rules, Constituency Pressures, and Pork Barrel: Bases of Voting in the Brazilian Congress". Journal of Politics, vol. 57, n-2, maio, pp. 324-343. . (2003), Os Entraves da Democracia no Brasil. Rio de Janeiro, FGV Editora.

AMORIM NETO, Octavio e SANTOS, Fabiano. (2001), “A Conexão Presidencial: Facções Pró e Antigoverno e Disciplina Partidária no Brasil”. DADOS - Revista de Ciências Sociais, vol. 44, no 2, pp. 2-17.

BARROS, Francisco. (2010), Federação, Bicameralismo, Democracia: Aspectos da Representação Política e da Dinâmica do Senado Federal no Brasil Pós-88. Dissertação de Mestrado em Ciência Política, Belo Horizonte, Universidade Federal de Minas Gerais.

BOND, Jon e FLEISCHER, Richard. (1990), The President in the Legislative Arena. Chicago, The University of Chicago Press.

BRANCO, Marcelo S. (2008), “A Atuação do Senado Federal no Processo de Ajuste Fiscal nos Anos 90", in L. Lemos (org.), O Senado Federal Brasileiro no Pós-Constituinte. Brasília, Unilegis, pp. 273-328.

CAREY, John M. (1999), "Party and Coalition Unity in Legislative Voting”. Working Paper no 376. Departamento de Ciência Política, Washington University at Saint Louis.

. (2007), “Competing Principals, Political Institutions, and Party Unity in Legislative Voting". American Journal of Political Science, vol. 51, no 1, pp. 92-107.

e REINHARDT, Gina. (2003), "Impacto das Instituições Estaduais na Unidade das Coalizões Parlamentares no Brasil". DADOS, vol. 46, no 4, pp. 773-804.

CARRUBBA, Clifford e VOLDEN, Craig. (2000), "Coalitional Politics and Logrolling in Legislative Institutions". American Journal of Political Science, vol. 44, no 2, pp. 261-277.

CARRUBBA, Clifford et alii. (2006), “Off the Record: Unrecorded Legislative Votes, Selection Bias and Roll Call Analysis". British Journal of Political Science, no 36, pp. 691-704.

CINTRA, Octávio. (2004), "O Sistema de Governo no Brasil”, in L. Avelar e A. O. Cintra (orgs.), Sistema Político Brasileiro: Uma Introdução. São Paulo, Editora da Unesp, pp. 61-78.

COX, Gary e McCUBBINS, Mathew. (1993), The Legislative Leviathan. Party Government in the House. Berkeley, University of California Press.

DESPOSATO, Scott. (2000), Institutional Theories, Societal Realities, and Party Politics in Brazil. Ph.D. Dissertation, University of San Diego.

(2003), "Comparing Group and Subgroup Cohesion Scores: A Nonparametric Method with an Application to Brazil". Political Analysis, vol. 11, no 3, pp. 275-289.

. (2005), “Correcting for Small Group Inflation of Roll-Call Cohesion Scores". British Journal of Political Science, vol. 35, no 4, pp. 731-744. 


\section{Pedro Robson Pereira Neiva}

(2006), "The Impact of Electoral Rules on Legislative Parties: Lessons from the Brazilian Senate and Chamber of Deputies". The Journal of Politics, vol. 68, no 4, pp. 1015-1027.

DUVERGER, Maurice. (1954), Political Parties. London, Menthuen.

FIGUEIREDO, Argelina e LIMONGI, Fernando. (1995), "Partidos Políticos na Câmara dos Deputados: 1989-1994". DADOS, vol. 38, no 3, pp. 497-524.

. (1996), O Congresso Nacional: Organização, Processo Decisório e Produção Legal. Cadernos de Pesquisa no 5, Cebrap, pp. 1-97.

. (1999), Executivo e Legislativo na Nova Ordem Constitucional. Rio de Janeiro, FGV Editora.

(2008), Política Orçamentária no Presidencialismo de Coalizão. Rio de Janeiro, FGV Editora.

GIANNETTI, Daniela e LAVER, Michael. (2008), “Party Cohesion, Party Discipline and Party Factions in Italy", in D. Giannetti e K. Benoit (orgs.), Intra-Party Politics and Coalition Governments. New York, Routledge, pp. 146-168.

LAMOUNIER, Bolívar e MENEGUELLO, Rachel. (1986), Partidos Políticos e Consolidação Democrática: O Caso Brasileiro. São Paulo, Brasiliense.

LEMOS, Leany (org.). (2008), “O Senado Federal Brasileiro no Pós-Constituinte”.Brasília, Edições Unilegis de Ciência Política, vol. 4.

e RANINCHESKI, Sonia. (2002), “O Perfil Sócio-Político dos Senadores Brasileiros". Senatus, vol. 2, no 1, pp. 33-39.

LIMA JÚNIOR, Olavo Brasil. (1993), Democracia e Instituições Políticas no Brasil dos Anos 80. São Paulo, Edições Loyola.

LIMONGI, Fernando e FIGUEIREDO, Argelina. (1998), Relação Executivo-Legislativo no Presidencialismo Multipartidário: Os Regimes de 46 e 88. Trabalho apresentado no XXII Encontro Anual da Anpocs, Caxambu, MG, 27 a 31 de outubro.

LOUREIRO, Maria Rita. (2001), "O Senado no Brasil Recente: Política e Ajuste Fiscal”. São Paulo em Perspectiva, vol. 15, no 4, pp. 53-60.

LYNE, Mona. (2005), “Parties as Programmatic Agents". Party Politics, vol. 11, no 2, pp. 193-216.

MAINWARING, Scott. (1991), “Políticos, Partidos e Sistemas Eleitorais: O Brasil numa Perspectiva Comparativa". Novos Estudos Cebrap, no 29, pp. 34-58.

. (2001), Sistemas Partidários em Novas Democracias: O Caso do Brasil. Porto Alegre, Mercado Aberto.

e SCULLY, Timothy. (1995), Building Democratic Institutions: Party Systems in Latin America. Stanford, Stanford University Press.

e PEREZ-LIÑAN, Anibal. (1997), "Party Discipline in the Brazilian Constitutional Congress". Legislative Studies Quarterly, vol. 22, no 4, pp. 453-483.

MAcRAE, JR., Duncan. (1967), Parliament, Parties and Society in France, 1946-1958. New York, St. Martin's Press. 


\section{Coesão e Disciplina Partidária no Senado Federal}

MATTHEWS, Donald. (1959), "The Folkways of the United States Senate: Conformity to Group Norms and Legislative Effectiveness". American Political Science Review, no53, pp. 1064-1089.

MENEGUELLO, Rachel. (1998), Partidos e Governos no Brasil Contemporâneo (1985-1997). São Paulo, Paz e Terra.

MICHELS, Robert. (1962), Political Parties. New York: Free Press.

MORGENSTERN, Scott. (2004), Patterns of Legislative Politics: Roll Call Voting in Latin America and the United States. New York, Cambridge University Press.

NEIVA, Pedro. (2006), "Os Determinantes da Existência e dos Poderes das Câmaras Altas: Federalismo ou Presidencialismo?" DADOS, vol. 49, no 2, pp. 269-299.

. (2009), Bicameralism and Budget Deficit Revisited. Trabalho apresentado no 21o Congresso Mundial de Ciência Política, Santiago, Chile, 12 a 16 de julho.

e IZUMI, Maurício. (2012), “Os Ilustres Sem-Votos do Legislativo: Perfil e Atuação dos Suplentes de Senadores no Brasil". Opinião Pública, vol. 18, no 1.

NICOLAU, Jairo. (2000), “Disciplina Partidária e Base Parlamentar na Câmara dos Deputados no Primeiro Governo de Fernando Henrique Cardoso (1985-1998)". DADOS, vol. 43, no 4, pp. 709-734.

OLSON, Mancur. (1965), The Logic of Collective Action: Public Goods and the Theory of Groups. Cambridge, Harvard University Press.

e MEZEY, Michael. (1991), Legislatures in the Policy Process: The Dilemmas of Economic Policy. Cambridge, Cambridge University Press.

PEREIRA, Carlos e MUELLER, Bernardo. (2004), "The Cost of Governing: Strategic Behavior of the President and Legislators in Brazil's Budgetary Process". Comparative Political Studies, vol. 20, no 1, pp. 1-32.

RICE, Stuart. A. (1924), Farmers and Workers in American Politics. New York, Columbia University.

RICCI, Paolo. (2008), “A Produção Legislativa de Iniciativa Parlamentar no Congresso: Diferenças e Similaridades entre a Câmara dos Deputados e o Senado Federal", in L. Lemos (org.), O Senado Federal Brasileiro no Pós-Constituinte. Brasília, Edições Unilegis de Ciência Política, vol. 4, pp. 237-271.

SANTOS, Fabiano. (1997), "Patronagem e Poder de Agenda na Política Brasileira". DADOS, vol. 40, no 3, pp. 465-491.

. (2000), “Deputados Federais e Instituições Legislativas no Brasil: 1946-1999”, in R. Boschi; F. Santos e E. Diniz (eds.), Elites Políticase Econômicas no Brasil Contemporâneo: A Desconstrução da Ordem Corporativa e o Papel do Legislativo no Cenário Pós-Reformas. São Paulo, Konrad Adenauer, pp. 91-117.

. (2002), “Partidos e Comissões no Presidencialismo de Coalizão". DADOS, vol. 45, no 2, pp. 237-264.

. (2003), O Poder Legislativo no Presidencialismo de Coalizão. Belo Horizonte, Editora UFMG.

SARTORI, Giovanni. (1993), "Nem Presidencialismo, Nem Parlamentarismo". Novos Estudos Cebrap, vol. 35, pp. 3-20. 


\section{Pedro Robson Pereira Neiva}

SINCLAIR, Barbara. (1989), The Transformation of the U. S. Senate. Baltimore, John Hopkins University Press.

TEIXEIRA, Henrique. (2009), Outorgas e Renovações de Rádio e TV: A Radiodifusão no Senado Federal 1999-2008. Monografia de Curso de Especialização em Processo Legislativo. Cefor - Câmara dos Deputados.

TSEBELIS, George. (1995), “Decision Making in Political Systems: Veto Players in Presidentialism, Parliamentarism, Multicameralism, and Multipartism". British Journal of Political Science, vol. 25, pp. 289-325. 
Coesão e Disciplina Partidária no Senado Federal

Apêndice 1

Índice de Rice (não corrigido)

\begin{tabular}{l|c|c|c}
\hline Partido & Senado & Câmara & Diferença \\
\hline PMDB & 0,69 & 0,73 & $-0,04$ \\
PFL/DEM & 0,77 & 0,82 & $-0,05$ \\
PSDB & 0,78 & 0,83 & $-0,05$ \\
PT & 0,91 & 0,96 & $-0,05$ \\
PTB & 0,80 & 0,78 & $+0,02$ \\
PDT & 0,82 & 0,85 & $-0,03$ \\
PPB & 0,78 & 0,73 & $+0,05$ \\
PSB & 0,92 & 0,86 & $+0,06$ \\
PPS & 0,97 & 0,83 & $+0,14$ \\
PPR & 0,71 & 0,74 & $-0,03$ \\
\hline Todos & $\mathbf{7 8 , 5}$ & $\mathbf{8 1 , 2}$ & $-\mathbf{2 , 7}$ \\
\hline
\end{tabular}

Fonte: Arquivo do Senado e banco de dados legislativos do Cebrap.

Cálculos efetuados pelo autor. 


\section{ABSTRACT \\ Party Cohesion and Discipline in the Brazilian National Senate}

This article analyzes party discipline in the Brazilian Senate based on a previously untapped database covering roll call votes from 1989 to 2009. As occurs in the Chamber of Deputies, political parties in the Senate display a high degree of unity that remains reasonably stable over time. Despite the similar results in the two Houses, I suggest that the explanations are not the same. As compared to the Chamber of Deputies, the Senate appears to feel less power from the Executive, the leaders are scarcely relevant, and the decision-making process is less centralized. I do not offer a solution to this paradox, but I do suggest that it involves not only the institutional rules, but also the organizational characteristics and even the political profile of the Senators themselves.

Key words: Legislative; Senate; discipline; cohesion; College of Leaders; party system; political elites

\section{RÉSUMÉ}

\section{Cohésion et Discipline des Partis au Sénat Fédéral Brésilien}

Dans cet article, on évalue la discipline des partis au Sénat fédéral, à partir de données inédites qui englobent les scrutins nominaux effectués pendant 21 ans, de 1989 à 2009. De même qu'à la chambre des députés, les partis du sénat ont manifesté une forte unité, assez stable au cours des années. Malgré les similitudes rencontrées dans les résultats pour les deux chambres législatives, les justifications ne semblent pas être les mêmes. Si on assiste aux débat des députés, la force du pouvoir exécutif au sénat semble moindre, ses leaders, moins importants et le processus décisionnel, moins centralisé. On ne propose pas de solution à ce paradoxe, mais il semble qu'elle réside non seulement dans les règles institutionnelles mais aussi dans les caractéristiques organisationnelles, voire dans le profil politique des sénateurs.

Mots-clés: pouvoir législatif; sénat; discipline; cohésion; collège des leaders, système de partis; élites politiques 